\title{
Development of bioreporter assays for the detection of bioavailability of long-chain alkanes based on the marine bacterium Alcanivorax borkumensis strain SK2
}

\author{
Rekha Kumari, ${ }^{1 \dagger}$ Robin Tecon, ${ }^{1 \ddagger}$ Siham Beggah, ${ }^{1}$ \\ Rebecca Rutler, ${ }^{2}$ J. Samuel Arey ${ }^{2}$ and \\ Jan Roelof van der Meer ${ }^{1 *}$ \\ ${ }^{1}$ Department of Fundamental Microbiology, University of \\ Lausanne, 1015 Lausanne, Switzerland. \\ ${ }^{2}$ Environmental Chemistry Modeling Laboratory, Ecole \\ Polytechnique Fédérale de Lausanne, 1015 Lausanne, \\ Switzerland.
}

\section{Summary}

Long-chain alkanes are a major component of crude oil and therefore potentially good indicators of hydrocarbon spills. Here we present a set of new bacterial bioreporters and assays that allow to detect longchain alkanes. These reporters are based on the regulatory protein AlkS and the alkB1 promoter from Alcanivorax borkumensis SK2, a widespread alkane degrader in marine habitats. Escherichia coli cells with the reporter construct reacted strongly to octane in short-term ( $6 \mathrm{~h}$ ) aqueous suspension assays but very slightly only to tetradecane, in line with what is expected from its low water solubility. In contrast, long-term assays (up to 5 days) with $\boldsymbol{A}$. borkumensis bioreporters showed strong induction with tetradecane and crude oil. Gel-immobilized $A$. borkumensis reporter cells were used to demonstrate tetradecane and crude oil bioavailability at a distance from a source. Alcanivorax borkumensis bioreporters induced fivefold more rapid and more strongly when allowed physical contact with the oil phase in standing flask assays, suggesting a major contribution of adhered cells to the overall reporter signal. Using the flask assays we further demonstrated the effect of oleophilic nutrients and biosurfactants on oil availability and degradation by $\boldsymbol{A}$. borkumensis. The fluorescence signal from flask assays could easily be

Received 28 April, 2011; accepted 24 May, 2011. *For correspondence. E-mail janroelof.vandermeer@unil.ch; Tel. (+41) 41 21692 5630; Fax (+41) 21692 5605. Present addresses: +Department of Zoology, Miranda House, University of Delhi, Delhi, India; ‡Department of Microbial Ecology, Netherlands Institute of Ecology (NIOO-KNAW), Wageningen, the Netherlands. captured with a normal digital camera, making such tests feasible to be carried out on, e.g. marine oil responder vessels in case of oil accidents.

\section{Introduction}

Saturated hydrocarbons (alkanes) are a major component of crude oil that can sometimes represent more than $50 \%$ of the total oil mass (Head et al., 2006). Certain marine environments are chronically exposed to oil via accidental spillages, offshore platform exploitation and shipping activities. Recent accidents have underscored the magnitude of oil spill contaminations and the difficulty to properly assess oil distribution and its availability to biota, in terms of both toxicity and biodegradation (Camilli et al., 2010). It would thus be useful to have improved tools to estimate the bioavailability of petroleum hydrocarbons in marine systems. Monitoring of the alkanes from oil can be used as a reliable indicator for recent oil pollution and bioreporter technology has been proposed as valuable alternative for chemical analytics in particular where this concerns bioavailability determinations (Tecon and van der Meer, 2008; van der Meer and Belkin, 2010). Unfortunately, the major difficulty for sensing oil using bacteria or other microbes is the extremely poor water solubility of most alkanes. As example, the alkane-sensing bioreporter Escherichia coli DH5 $\alpha$ (pGEc74, pJAMA7) was developed for the detection of $\mathrm{C}_{6}-\mathrm{C}_{11}$-alkanes more than 10 years ago but does not measurably detect tetradecane (Sticher et al., 1997). This bioreporter was based on the AlkS gene and the $\mathrm{P}_{\text {alkB }}$ promoter of Pseudomonas oleovorans (now P. putida Gpo1). It was recently used in estimations of volatile alkane dissolution in simulated marine oil spills with a method of detection limit of $0.04 \mu \mathrm{M}$ octane (Tecon et al., 2010). In oil-contaminated environments, however, short-chain alkanes volatilize rapidly and can only be detected during a short period, which makes them less suitable as marker for 'older' contaminations. More recently, Zhang et al. described a luciferase bioreporter for long-chain alkanes based on Acinetobacter baylyi ADP1 that was induced by dodecane, tetradecane and octadecane (Zhang et al., 2010), which may also prove useful in marine oil spills. 
The marine bacterium Alcanivorax borkumensis is a ubiquitous $\gamma$-Proteobacterium, which was isolated for its ability to use alkanes as sole source of carbon and energy (Yakimov et al., 1998; Sabirova et al., 2006). Although usually found in low numbers in pristine environments, A. borkumensis rapidly becomes a dominant member of the bacterial community when oil pollution is present (Kasai et al., 2002; Hara and Harayama, 2003). The type strain A.borkumensis SK2, of which the complete genome sequence was recently published (Schneiker et al., 2006), contains the alkSB ${ }_{1} G H J$ operon, which is involved in the degradation of alkanes (van Beilen et al., 2004; Hara et al., 2004). Expression of alkB ${ }_{1} G H J$ is controlled from the $\mathrm{P}_{\text {alkB1 }}$ promoter (alkB1p) by the transcriptional activator AlkS $_{\mathrm{Ab}}$, which shares $27 \%$ overall amino acid similarity with AlkS of P. putida Gpo1 (van Beilen et al., 2004). Other functions in strain SK2 are supposed to contribute to the degradation of longer and branched chain alkanes, such as three P450 cytochromes and a second alkane hydroxylase AlkB2 (van Beilen et al., 2004; Hara et al., 2004; Schneiker et al., 2006).

The goal of the present work was to construct a bioreporter suitable for measuring bioavailability and bioaccessibility of longer chain alkanes $\left(>\mathrm{C}_{11}\right)$ in marine systems. Since the alkB1p from $A$. borkumensis species AP1 and SK2 was reported as being inducible during growth on n-tetradecane or hexadecane (van Beilen et al., 2004; Sabirova et al., 2006; Schneiker et al., 2006), we constructed a reporter circuit consisting of AlkS $_{A b}$ and its cognate alkB1p from SK2, fused to either bacterial luciferase (LuXAB) or egfp as reporters. The reporter circuit was introduced on plasmid DNA both in $E$. coli and in strain SK2 itself. Inducibility with octane, tetradecane and crude oil was first tested in short-term (6 h) lowdensity reporter cell suspensions. For longer-term detection of bioaccessible fractions we used diffusion assays by which water-soluble and diffusible oil components can be measured over a period of days to the SK2 reporter cells. Finally, we employed long-term (5 days) flask assays to record the cumulative signal from A. borkumensis bioreporter cells in suspension and adhered to droplets during periods of up to a week. To demonstrate the usefulness of the assays, we tested the effect of commercial oleophilic nutrients and biosurfactant on the long-term A. borkumensis reporter response with crude oil and with tetradecane, while correlating this to oil degradation.

\section{Results}

Development of an A. borkumensis-based alkane reporter

In order to obtain a bioreporter for long-chain alkanes we employed the alkS $S_{A b}$ gene (under its native promoter) and the $\mathrm{AlkS}_{\mathrm{Ab}}$-dependent alkB $B_{1}$ promoter from $A$. borkumensis SK2 to control expression of the egfp or luxAB reporter genes (Fig. 1A). The AlkS $\mathrm{Ab}_{\mathrm{b}}-\mathrm{alkB1p}$ system was functional in E. coli $\mathrm{DH} 5 \alpha$, with egfp fluorescence and bioluminescence becoming two- to fivefold induced in aqueous suspension assays in the presence of octane compared with an unexposed control, and depending on the gasliquid phase ratio in the assay (Fig. 2). Addition of watersaturating amounts of tetradecane to a suspension of E. coli $\mathrm{DH} 5 \alpha$ (pAlk8) cells resulted in a very small (1.2fold) but statistically significant $(P<0.05)$ increase of egfp signal after $6 \mathrm{~h}$ incubation time (Fig. 2A). Tetradecane did not measurably induce luciferase expression from the same circuit in E. coli (pAlk5, not shown). Induction assays with varying concentrations of octane and the luciferase reporter $E$. coli $\mathrm{DH} 5 \alpha$ (pAlk5) produced similar response curves (Fig. 2C) as with E. coli DH5 $\alpha$ (pGEc74, pJAMA7), which drives luciferase expression from the alkB promoter of $P$. putida Gpo1 (Sticher et al., 1997). We noticed that the uninduced background expression of luciferase in E. coli was fivefold higher with the SK2derived gene circuit than with that of Gpo1 (Fig. 2C). Interpolation of the response curve at a value of the blank plus three times its measured deviation resulted for both reporters in a method of detection limit for octane of $5 \mathrm{nM}$, at which the signal is 1.2-fold higher than in the blank. The same octane concentration induced the alkSAb-alkB1pegfp reporter to a lower level in A. borkumensis SK-3009 (pAlk8) than in E. coli, both after $6 \mathrm{~h}$ and both $24 \mathrm{~h}$ incubation (Fig. $2 A$ and B). As for E. coli tetradecane very poorly induced (1.2-fold) the alkSAb-alkB1p-egfp reporter circuit in $A$. borkumensis SK-3009 (pAlk8) during $6 \mathrm{~h}$ incubation time, a value which was statistically significant $(P<0.05)$ compared with the unexposed control but extremely small (Fig. 2). Interestingly, SK-3009 cells were much stronger induced with NSO-1 oil with induction factors of 2.0 and 4.2 after 6 and $24 \mathrm{~h}$ respectively (Fig. 2A and B). We thus concluded that the reporter was functioning both in $E$. coli and in $A$. borkumensis but that the response to tetradecane was very small, most likely because of the extremely poor aqueous-phase solubility $(0.04 \mu \mathrm{M})$.

\section{Diffusion assays for determining long-chain alkane bioavailability for $\mathrm{A}$. borkumensis at a distance from the source}

In contrast to simple short-term (6 h) incubation assays with suspended reporter cells where an immediately available but low concentration of alkanes could be dosed to the cells, we designed a diffusion assay similar as recently described for a phenanthrene reporter based on Burkholderia sartisoli (Tecon et al., 2009). The idea of the diffusion system is that the reporter cells experience a 


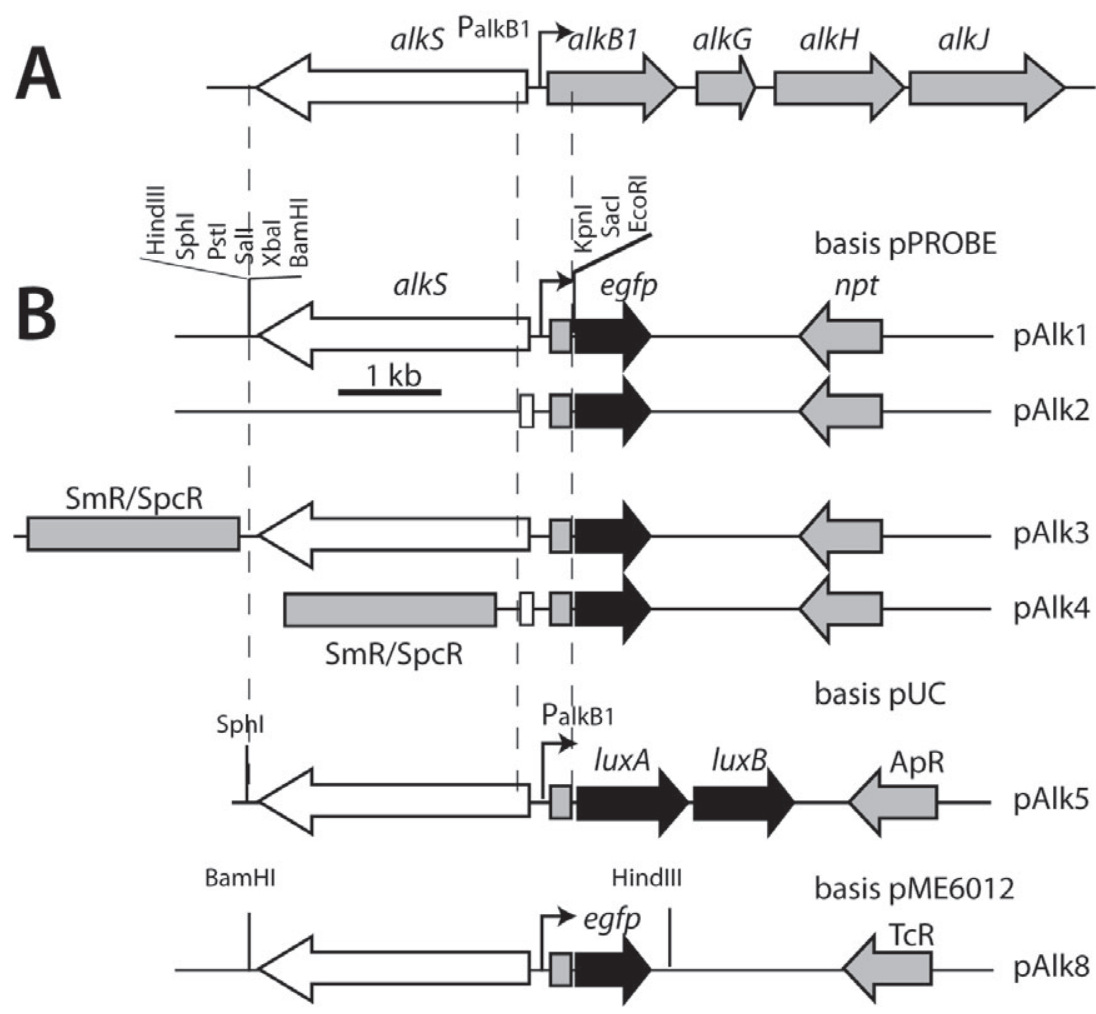

Fig. 1. Reporter gene constructs based on the alk system of $A$. borkumensis SK2.

A. The alkSB, GHJ operon from

$A$. borkumensis SK2 with the localization of the alkB1p promoter.

B. A $3 \mathrm{~kb}$ fragment (containing alkB1p and the full alkS $S_{A b}$ gene encoding the regulator AlkS $S_{A b}$ ) or a $0.4 \mathrm{~kb}$ fragment (containing only alkB1p plus flanking regions) was inserted upstream of the egfp reporter gene in pPROBE-gfp[tagless] (pAlk1, pAlk2) or upstream the luxAB genes in pJAMA8 (pAlk5). A Sp-resistance cassette was inserted in pAlk1 and pAlk2, producing the plasmids pAlk3 and pAlk4 respectively. Finally, a $4 \mathrm{~kb}$ fragment from pAlk1 was inserted in pME6012 to give pAlk8.

continuous compound flux from a source over time, by which a low signal from a poorly water-soluble inducer such as tetradecane is accumulated. The diffusion system can thus give an impression of bioaccessible fractions from a source (i.e. the compound availability over time). In addition, autofluorescence from oil microdroplets would be less likely to confound egfp measurements, because they are physically separated from the reporter cells. To avoid the possibility of oil slipping between the glass coverslip and the cells in the agarose, we solidified oil sources using eicosane $\left(\mathrm{C}_{20}\right.$ linear alkane), which is solid at room temperature. Figure 3 illustrates how $A$. borkumensis SK-3009 (pAlk8) reporter cells immobilized in a 2-cm-long and 1-mm-thick agarose patch respond to defined tetradecane or NSO-1-oil sources supplied by contact at one end to the patch. One can see that the egfp fluorescence is highest near the source and declines along the distance of the strip. Moreover, egfp fluorescence is increasing near the source over a period of 5 days. It can also be observed that the fluorescence signal is higher to $1 \%$ than to $0.1 \%$ tetradecane mixed with eicosane, and, likewise, higher to $10 \%$ than to $1 \%$ NSO-1 mixed with eicosane (Fig. $3 \mathrm{~A}$ and $\mathrm{B}$ ). This is counterintuitive because at these dosages the aqueous solubility should be the same and therefore, the concentration that is seen by the cells in the patch should be similar in each case. What therefore likely happens is that the $A$. borkumensis SK-3009 reporter cells multiply at the expense of oil components diffusing into the patch, and the increase of reporter signal is due to both an increase in biomass and induction. Attempts to control for this via a second constitutively expressed reporter in A. borkumensis SK-3009 were unfortunately not successful. The decline in reporter signal as a function of distance over the agarose strip is thus likely a consequence of both a longer diffusion path from the source and depletion by the cells in the areas closer to the source. This diffusion assay further demonstrates that in terms of bioaccessibility, diffusion from $1 \%$ tetradecane in eicosane into an aqueous environment at a distance from the source is perceived similarly by $A$. borkumensis as diffusion of components from 10\% NSO-1 oil (Fig. 3). To show this effect more clearly, we calculated the increase in total fluorescence reporter signal across the complete patch area as a function of incubation time (Fig. 4A and B). Although measurement variations amplify in this signal integration process (e.g. Day 3 to 4 in Fig. 4A), one can see that the kinetics of reporter increase to $1 \%$ tetradecane and 10\% NSO-1 (or, for that matter, $0.1 \%$ tetradecane and $1 \% \mathrm{NSO}-1$ ) is similar, and therefore, that the available amount of material in 10\% NSO-1 crude oil for $A$. borkumensis in the aqueous phase is equivalent to $1 \%$ tetradecane (or $1 \%$ NSO-1 and $0.1 \%$ tetradecane). Independent repetitions of diffusion strips gave quite equivalent results, although there was a definite variability, which was likely due to preparation and assembly of the strips, and of the oil 


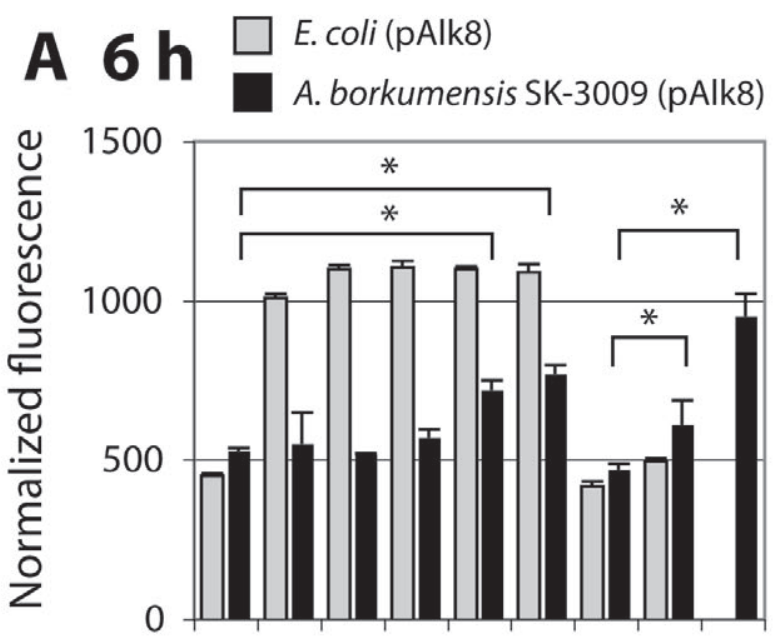

\section{B $24 \mathrm{~h}$}

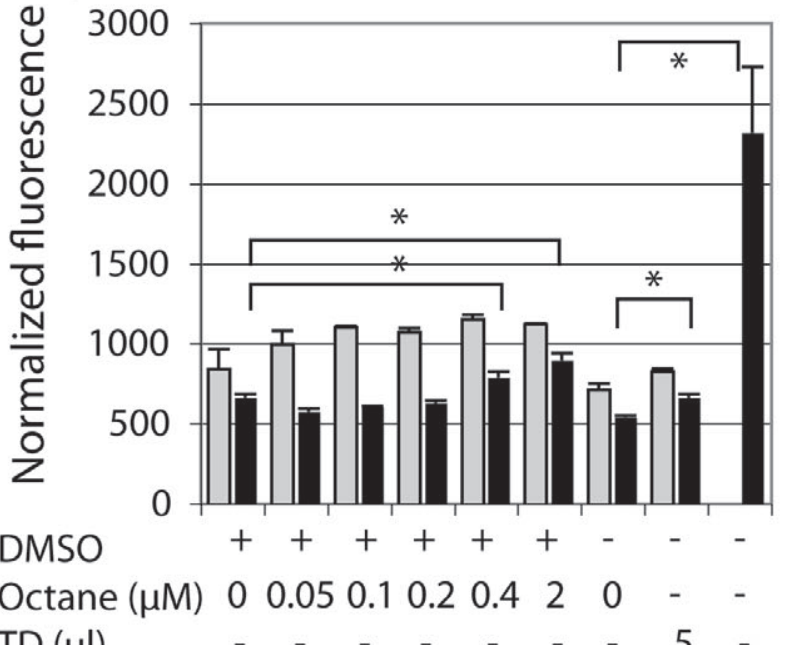

TD $(\mu \mathrm{l})$

NSO1 $(\mu \mathrm{l}) \quad-\quad-\quad-\quad-\quad-\quad-\quad-\quad-10$

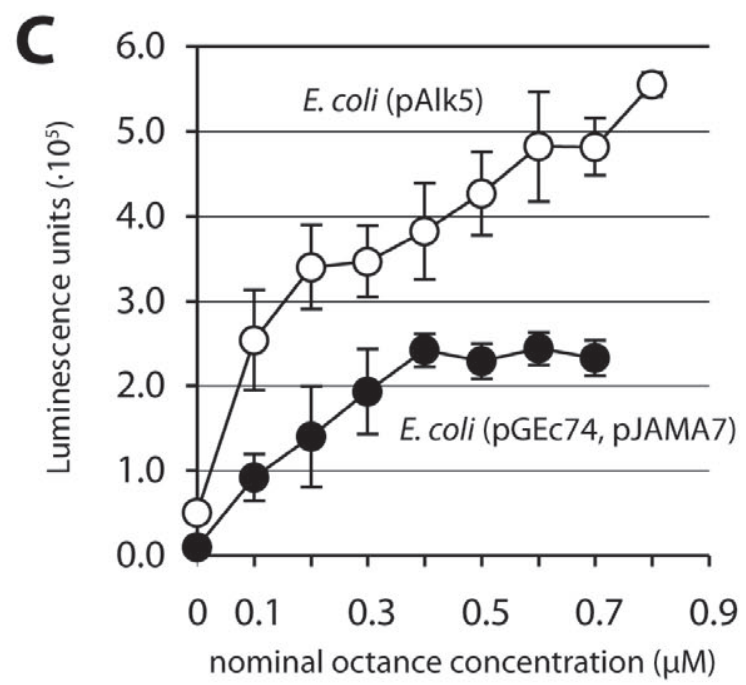

Fig. 2. Alkane induction of the alkSAb-alkB1p system in aqueous-phase short-term assays.

A. Assay incubation of $6 \mathrm{~h}$ in vials filled without head space.

B. As (A), but assayed after $24 \mathrm{~h}$ incubation.

C. Luciferase reporter induction with varying concentrations of octane in case of the alkB $B_{1}$ promoter (A. borkumensis) in $E$. coli $\mathrm{DH} 5 \alpha$ (pAlk5) and of the alkB promoter (P. putida Gpo1) in E. coli $\mathrm{DH} 5 \alpha$ (pGEc74, pJAMA7) in vials with 1:1 gas and liquid phase, measured after $2 \mathrm{~h}$ incubation time.

Error bars indicate standard deviations calculated from fivefold assays. Asterisks indicate significant differences in pair-wise $t$-test (two-tailed, equal variance, $P<0.05$ ).

source (e.g. $1 \%$ tetradecane in eicosane in Fig. 4A-C). In terms of bioaccessibility one can further conclude that $1 \%$ tetradecane in eicosane is as easily perceivable by reporter cells as is $1 \%$ tetradecane in inert silicon oil. Furthermore, the cells do not react either to eicosane as a distant source or to silicon oil itself (Fig. 4C).

Oil bioavailability assays with A. borkumensis SK-3009 (pAlk8) in standing flasks

In contrast to diffusion assays where the $A$. borkumensis SK-3009 (pAlk8) reporter cells were located at a distance from the oil source, macro-scale long-term assays in
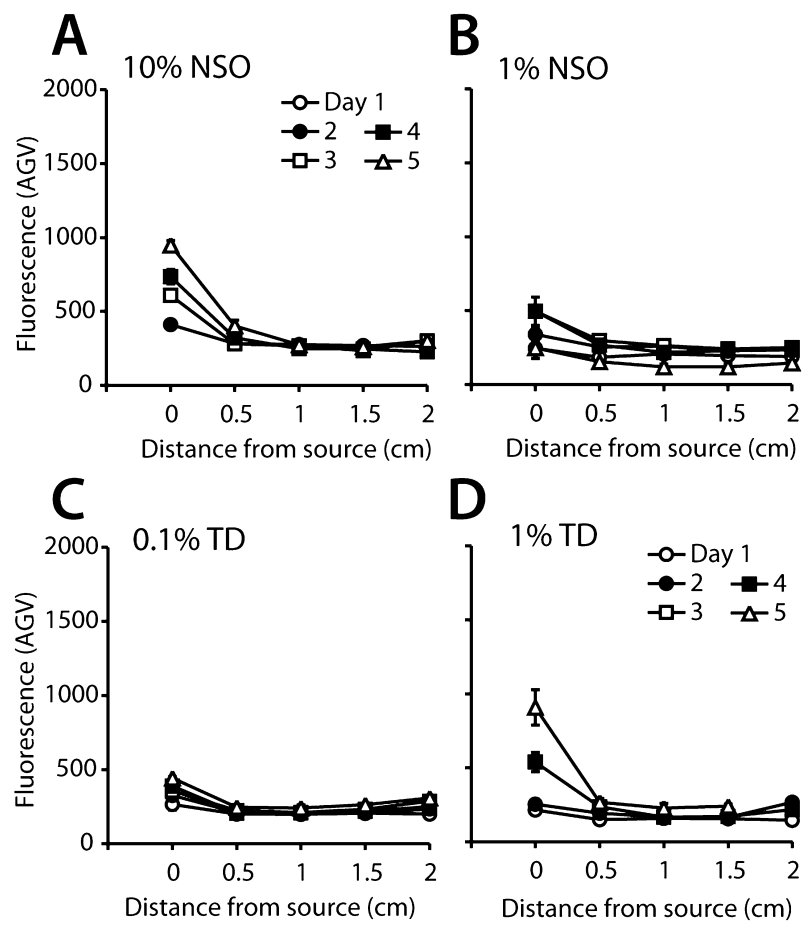

Fig. 3. Egfp reporter gene induction in A. borkumensis SK-3009 (pAlk8) as a function of distance to the oil source and incubation time (days): (A) 10\% v/v NSO-1 crude oil mixed with eicosane; (B) $1 \% \mathrm{v} / \mathrm{v}$ NSO-1 crude oil mixed with eicosane; (C) $0.1 \% \mathrm{v} / \mathrm{v}$ tetradecane (TD) mixed with eicosane; (D) $1 \% \mathrm{v} / \mathrm{v}$ TD mixed with eicosane. Egfp fluorescence determined by image analysis and expressed in arbitrary units (AGV) produced from $500 \mathrm{~ms}$ exposure by the camera (16-bit TIFF, 0-4800 units). 

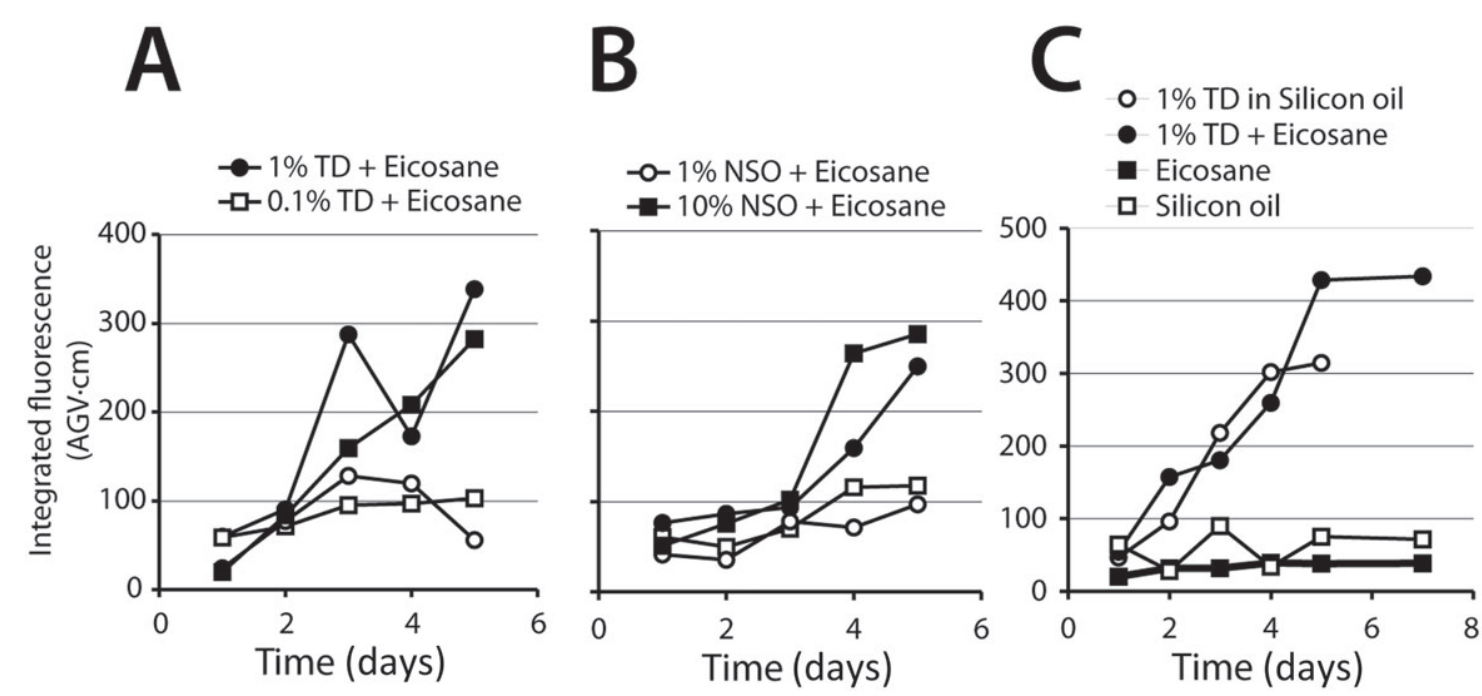

Fig. 4. Integrated kinetics of egfp formation from A. borkumensis SK-3009 (pAlk8) cells across distance in agarose diffusion patches. Data from Fig. 3.

A. Duplicate experiment with $1 \%$ and $0.1 \%$ tetradecane in eicosane.

B. Exposures to $1 \%$ and $10 \%$ NSO-1 in eicosane.

C. Comparison of $1 \%$ tetradecane in eicosane or silicon oil, and eicosane or silicon oil alone.

Note that the 'dip' seen in (A) in one of the signals is an artefact of the integration procedure.

standing flasks allowed detection of the cellular response to diffusible oil over a period of days while additionally permitting contact of the cells and the oil. We thought this might be of particular importance for the A. borkumensis reporter cells, since the strain is known to produce biosurfactants and adheres strongly to oil droplets (Fig. 5G), both of which influence availability of alkanes to the cells. In contrast to the previous $6 \mathrm{~h}$ induction assays in aqueous suspension, standing flask assays demonstrated very clearly how tetradecane indeed is a significant inducer for A. borkumensis SK-3009 (pAlk8) with a fourfold egfp induction after 4-5 days compared with a control without tetradecane (Fig. 5D). Induction with $0.25 \%(\mathrm{v} / \mathrm{v}) \mathrm{NSO}-1$ crude oil in flasks was again much more rapid than with $0.5 \%(\mathrm{v} / \mathrm{v})$ tetradecane and resulted in 10-fold higher egfp fluorescence (Fig. 5A). Fluorescence of the reporter culture in such flasks was so bright that it was easily detectable by normal digital photography (Fig. 5F) and could also be quantified quite correctly from digitized flask image intensities (Fig. 5C-E). The exact nature of the compounds in NSO-1 that contribute to such rapid and strong induction levels is unclear, since neither octane nor tetradecane was potent enough to cause the same induction level of the alkSAb-alkB1p-egfp reporter in A. borkumensis SK-3009 (pAlk8) (Fig. 2).

\section{Effects of oleophilic nutrients or commercial surfactant on oil bioavailability and biodegradability}

Using the standing flask assays we next tested the effect of a number of regular treatments that are perceived to be favourable for oil degradation in marine systems (MedinaBellver et al., 2005). In particular, these consist of the addition of nutrients, oleophilic fertilizers or surfactants (Jiménez et al., 2006). The effect of having optimized nutrient conditions (ONR7a) compared with seawater on the response of $A$. borkumensis SK-3009 (pAlk8) reporter cells to crude oil was absolutely striking (Fig. 5A). Quantification of oil degradation after 7 days confirmed the reporter response by $A$. borkumensis SK-3009 (pAlk8) in that most alkanes (up to $\mathrm{C}_{40}$ ) were degraded to less than $50 \%$ of their original amount in the case of ONR7a medium (Fig. 6B), whereas essentially none was degraded in seawater without nutrients (Fig. 6A). We then tested the addition of a commercial oleophilic fertilizer S200 (Jiménez et al., 2006) to seawater on the reporter response and extent of alkane degradation after 7 days. Quite surprisingly, we noticed that addition of S200 at a concentration of $0.25 \%$ but less so at $0.1 \%$, and completely contrary at $1 \%$, resulted in an extremely fast and strong egfp fluorescent signal of the SK-3009 (pAlk8) cells to NSO-1 in seawater (Fig. 5B). S200 itself was not fluorescent, but the cells also reacted to the product alone with egfp formation, suggesting that some component of the industrial formulation induces the $\mathrm{AlkS}_{\mathrm{Ab}}-$ alkB1p reporter circuit in $A$. borkumensis. This suggested, therefore, a very positive effect of addition of $0.25 \% \mathrm{~S} 200$ on oil perception and perhaps degradation by $A$. borkumensis SK-3009 (pAlk8). Indeed, alkane degradation after 7 days had occurred and significantly more than in seawater alone, but still much less than with cells in ONR7a medium (Fig. 6A). Addition of S200 at 1\% turned out to be 

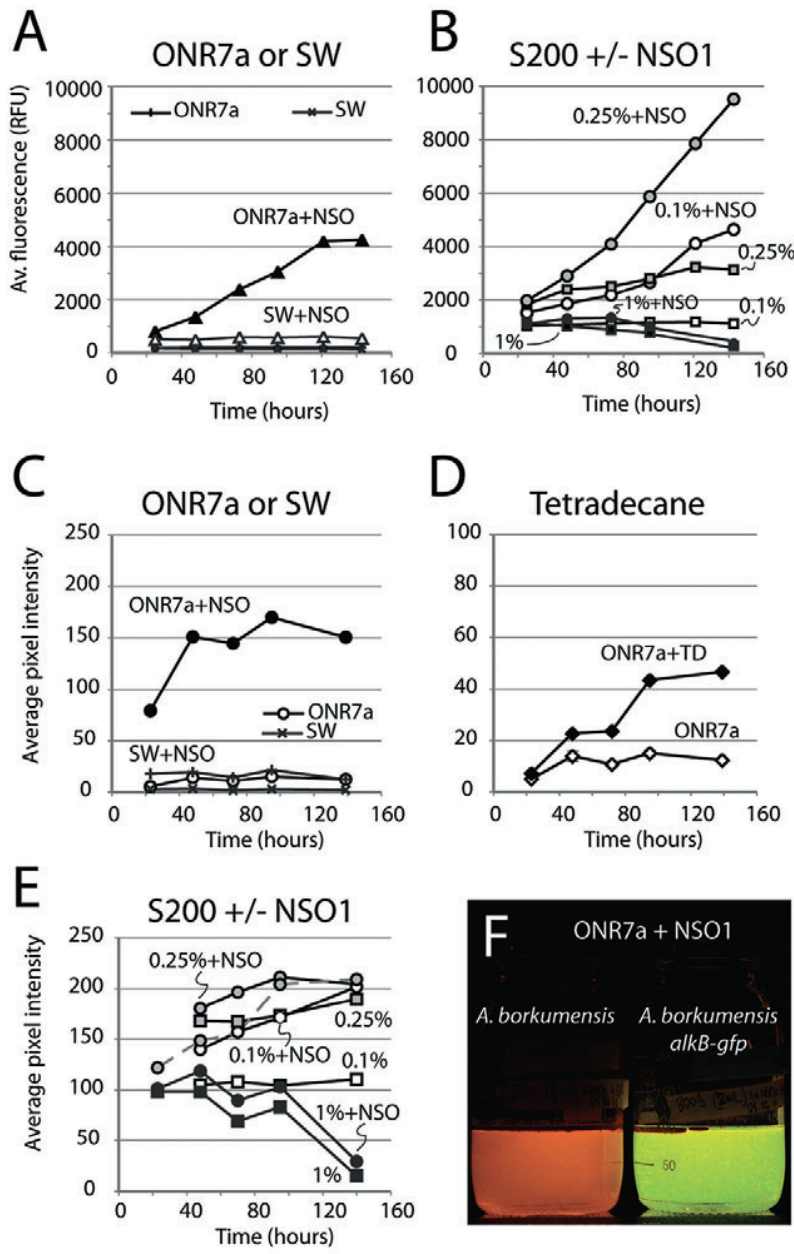

G phase contrast
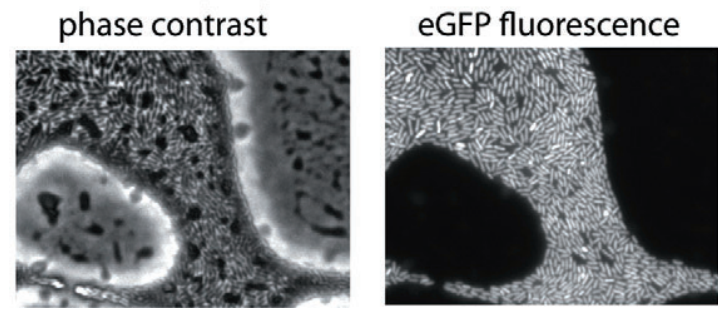

Fig. 5. Egfp reporter development in flask assays with A. borkumensis SK-3009 (pAlk8) supplemented with different oil sources and quantified per fluorimetry $(A$ and $B)$ or digital image analysis $(\mathrm{C}-\mathrm{F})$.

A. Effect of nutrients on NSO-1-dependent egfp induction in ONR7a medium or seawater (SW).

B. Effect of S200 oleophilic fertilizer on NSO-1-dependent egfp induction.

C. As (A), but measured by digital image analysis.

D. Tetradecane-dependent egfp induction in ONR7a medium.

E. As (B), but measured by digital image analysis. Note that the $0.25 \%$ S200 plus NSO- 1 assays was measured twice (grey circles, dotted line).

F. Fluorescence on a Dark Reader of flasks with $A$. borkumensis SK2 or A. borkumensis SK-3009 (pAlk8) on ONR7a medium with NSO-1 oil after 2-day incubation.

G. Detail of $A$. borkumensis SK-3009 (pAlk8) cells adhering to NSO-1 oil droplets after 2-day incubation. completely uneffective and possibly even toxic to the cells. Next, we tested the potential effect of a commercial rhamnolipid biosurfactant JBR215 at the suggested critical micelle concentration of $0.1 \%$ (Gu and Chang, 2001), both on alkane degradation and on reporter gene induction by $A$. borkumensis SK-3009 (pAlk8) to $0.25 \%$ NSO-1 in seawater. In this case, however, no significant increase in egfp signal was obtained compared with seawater alone, neither did JBR215 itself result in any response of the cells (not shown). In contrast, reporter cells had degraded slightly but significantly more alkanes in the
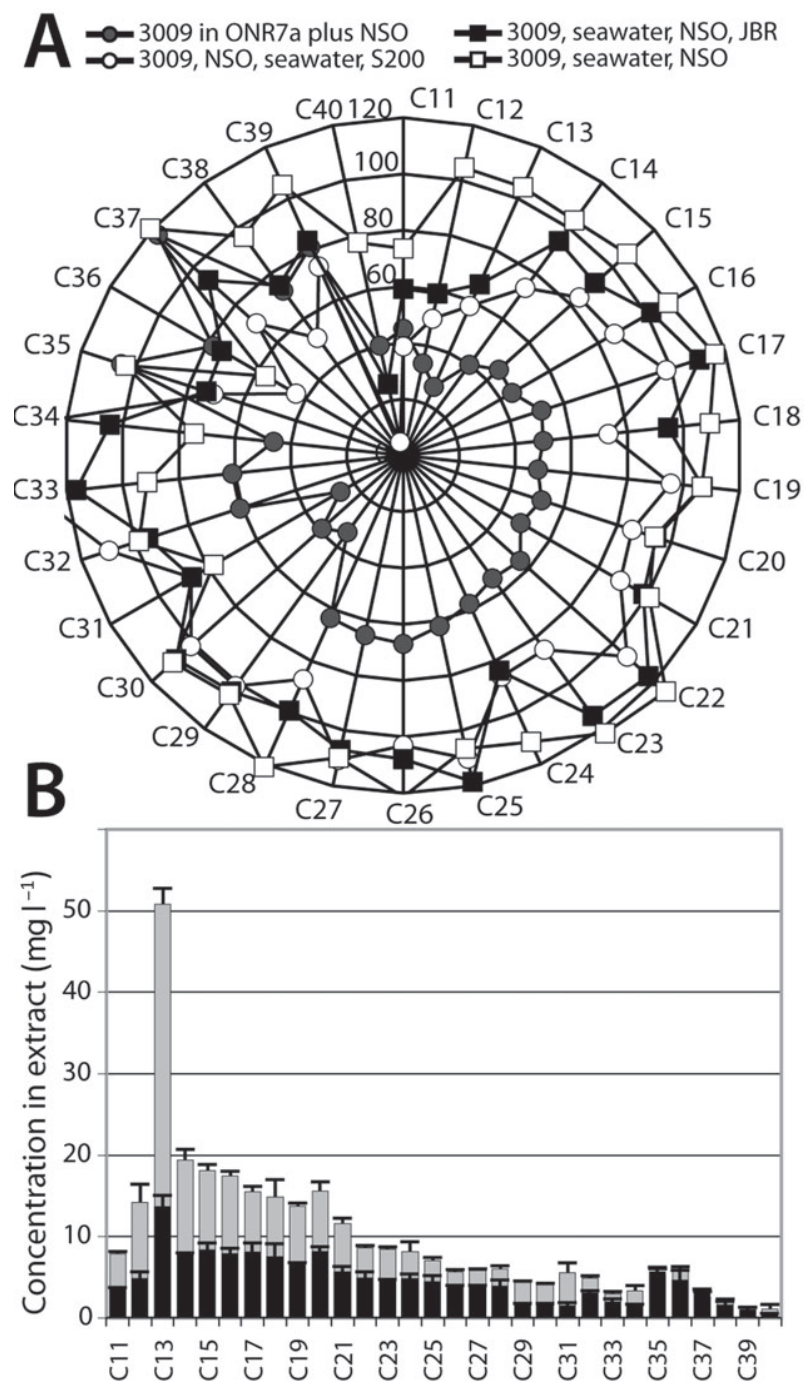

Fig. 6. Alkane concentrations in flask incubations with or without A. borkumensis SK-3009 (pAlk8) and NSO-1 crude oil after 7 days, in seawater or ONR7a medium, in presence or absence of S200 oleophilic fertilizer or JBR215 biosurfactant.

A. Percentage remaining linear alkane in flask compared with uninoculated control incubated for 7 days.

B. Alkane concentration in dichloromethane extract from flasks after 7 days for uninoculated controls (grey bars) or inoculated with SK-3009 (black bars) 
$\mathrm{C}_{11}-\mathrm{C}_{13}$ range in the presence of JBR215 than without (Fig. 6A).

\section{Discussion}

We developed a set of new E. coli and A. borkumensis bioreporters for the detection of long-chain alkanes based on the AlkS $\mathrm{Ab}_{\mathrm{Ab}}$ regulator and the operator/promoter region of the alkB $B_{1} G H J$ operon from the marine bacterium $A$. borkumensis SK2 (Schneiker et al., 2006). The alkB 1 promoter has been reported as being induced during growth on tetradecane and hexadecane and, therefore, seemed a good candidate for construction of a reporter circuit. Our results indicate that the circuit faithfully reports the behaviour of the cognate alkB $B_{1}$ promoter and its biological function for $A$. borkumensis, i.e. mediating degradation of linear alkanes (Fig. 6). The downside of this behaviour is that short-term incubation assays with long-chain alkanes and the bioreporters produce relatively low reporter signals, as a consequence of the low availability of the alkanes as inducers for the cells (Fig. 2). Long-term incubation assays allow sufficient target compound flux to the cells and result in high magnitude reporter signals (Fig. 5). The long-term assays can be employed to study longchain alkane bioavailability and bioaccessibility in marine samples and the effect of physicochemical measures on this (Figs 5 and 6).

Induction of promoters such as alkB1p in $A$. borkumensis is - at first sight - puzzling and challenging to study. For example, around 40-fold more alkB1 mRNA was measured in SK2 RNA from exponentially grown cultures on tetradecane compared with stationary phase, but on a per cell basis this amounted to only $\sim 2$ alkB1 mRNAs (Schneiker et al., 2006), which is really a small number compared with other catabolic promoters (Leveau et al., 1999; Denef et al., 2005). This amount of alkB1 mRNA induction is of a similar magnitude as the recently reported fivefold higher levels detected in cultures of Alcanivorax dieselolei grown on tetradecane compared with acetate (Liu et al., 2011). van Beilen and co-workers showed stronger alkB1 mRNA levels in S1 nuclease protection assays of RNA from tetradecanegrowing $A$. borkumensis AP1 cells (a strain related to SK2) than from cultures growing on pyruvate, but without exact quantification (van Beilen et al., 2004). They also showed that the alkB1 promoter from strain AP1 is inducible by octane via complementation by AlkS from P. putida Gpo1 (van Beilen et al., 2004). Finally, in a proteome study, AlkB1 was absent on 2D gels with protein extract from pyruvate-grown cultures but present in hexadecane-grown cells (Sabirova et al., 2006). Indeed, the alk $S_{A b}-a l k B 1 p$ circuit was induced with octane in $E$. coli either with LuxAB or with egfp reporters in $6 \mathrm{~h}$ aqueous suspension assays (Fig. 2). The calcu- lated method of detection limit for octane was $5 \mathrm{nM}$ in closed vials with $50 \%$ head space for the E. coli with the alkS $S_{A b}-$ alkB1p-luxAB circuit. This is similar (Fig. 2C) to what could be achieved with a previously developed E. coli reporter based on the alkS-alkBp from P. putida Gpo1 (Sticher et al., 1997; Jaspers et al., 2001), although we noticed that background expression in E. coli from alkS $S_{A b}-a l k B 1 p$ is fivefold higher than from alkS-alkBp.

In contrast, direct induction with tetradecane in a $6 \mathrm{~h}$ suspended cell assay of both E. coli (pAlk8) and A. borkumensis SK-3009 (pAlk8) was extremely poor with an estimated (statistically significant, $P<0.05$ ) 1.2-fold higher egfp reporter signal than the unexposed control (Fig. 2). In contrast, the water-dissolved part of crude oil resulted in a much stronger induction of SK-3009 (pAlk8) cells, even in a $6 \mathrm{~h}$ incubation assay (Fig. 2). This suggests that other linear and/or branched alkanes may be better immediate inducers for the alkB1p than octane, tetradecane or eicosane $\left(\mathrm{C}_{20}\right.$, Fig. $\left.4 \mathrm{C}\right)$, but these were not further identified here. This would be in agreement with recent results on alkB1 induction in $A$. dieselolei, a strain related to SK2 (Liu et al., 2011). In long incubation assays (5 days) with the A.borkumensis SK-3009 (pAlk8) the egfp level was fourfold higher with tetradecane than in the control (Fig. 5D), showing that tetradecane is indeed an inducer for alkB1p. The difference between short and long-term incubation assays indicates that the induction kinetics by tetradecane is primarily governed by the extremely low water solubility. In a short-term aqueous-phase assay only dissolved tetradecane is available to the cells $(\sim 0.04 \mu \mathrm{M})$, as a consequence of which very few inducer molecules trigger the reporter circuit. Assuming that tetradecane is maximally dissolved, its $40 \mathrm{nM}$ concentration might have led to a similar response as $40 \mathrm{nM}$ octane. In reality, the response was slightly lower: 1.2-fold for $40 \mathrm{nM}$ tetradecane versus (calculated) 3.4-fold for $40 \mathrm{nM}$ octane in the LuxAB reporter and 2.2-fold in the egfp reporter. This suggests that there might be further differences between octane and tetradecane induction in E. coli, perhaps at the level of transport over the cell membranes. It is also not unlikely that tetradecane was incompletely dissolved and that the aqueous-phase concentration was even lower than $40 \mathrm{nM}$ (Sutton and Calder, 1974). The behaviour of the alkS $S_{A b}-a l k B 1 p-e g f p$ circuit was also not completely the same in E. coli and A.borkumensis with respect to inducibility with octane (Fig. $2 A$ and $B$ ). The same concentration of octane resulted in a lower egfp signal in SK2 compared with E. coli, which might be explained by degradation of octane by $A$. borkumensis cells and decrease in the available compound fraction for induction. Our results are therefore in agreement with published data on the alkB1p induction in A. borkumen- 
sis, indicating that immediate induction with long-chain alkanes is small and only becomes manifest during prolonged growth of the cells on the compound.

The aqueous solubility of tetradecane thus seems to be close to the lower limit of induction of the alkSAb-alkB1p system, if we assume that AlkS functioning depends directly on the aqueous (cytoplasmic) concentration of the target compound. Some evidence exists that AlkS might be a protein in physical association with the cytoplasmic membrane (Sabirova et al., 2006), in which case it could be induced directly by the higher concentration of alkanes in the lypophilic membrane. Therefore, longer exposure either to a source of constantly dissolving tetradecane as in the diffusion assays - or to active biological attachment and dissolution of a source - as in long-term assays with secondary oil or tetradecane phase - is necessary for more optimal induction of this promoter. Indeed, SK-3009 (pAlk8) cells immobilized in agarose accumulated up to 10-fold more reporter signal over a period of 7 days when having a constant source of (but not direct contact to) tetradecane (Fig. 4C). We could show that increasing the bioaccessible fraction of tetradecane in the source led to a higher and faster signal development in the diffusion strips (Fig. 4A). Interestingly, the diffusion tests also indicated that a $10 \%$ crude oil source in eicosane is perceived similarly as $1 \%$ tetradecane by the reporter cells, and $1 \%$ crude oil similar as $0.1 \%$ tetradecane (Fig. 4).

Reporter signals increased even more dramatically when allowing SK-3009 (pAlk8) cells to contact the oil phases (Fig. 5). Overall biomass corrected egfp intensities from SK-3009 (pAlk8) in flask assays with tetradecane were four times higher than in unexposed controls that contained the same amount of pyruvate, and 10-fold higher with NSO-1 crude oil (Fig. 5). Whereas 10\% NSO-1 in diffusion assays produced a similar reporter signal by SK-3009 (pAlk8) cells as 1\% tetradecane, $0.25 \%$ NSO-1 in a flask resulted in a five times higher and five times faster response of cells as $0.5 \%$ tetradecane (Fig. 5C and D). Since cells in the diffusion agarose strips are physically separated from the oil source, the favourable response in flasks must come from cells adhering to oil droplets or solubilizing them via production of biosurfactants. Since the egfp signal obtained in flask assays is a combination of signal from cells attached to microdroplets and from those fully in suspension, it would be interesting to discriminate the reporter signal contribution of attached cells versus cells freely in suspension. Unfortunately, we could not properly quantify egfp signals of SK-3009 (pAlk8) cells adhering to oil droplets because of poor resolution of cells to the edge of droplets and because of background fluorescence of aromatic compounds in oils (Fig. 5F and G). However, given that diffusion assays showed poorer induction of cells at a distance from the oil phase than cells in flasks with contact to oil, this suggests that cells in aqueous phase in the flask assay are less induced by the long-chain alkanes, or are preferentially induced by more soluble short-chain alkanes from crude oil. Alternatively, the subpopulation of cells that attaches directly onto oil or tetradecane microdroplets solubilize part of the compound by producing biosurfactants and make them more available to their partner cells remaining in solution.

Following the reaction of SK-3009 reporter cells in flask assays proved remarkably easy while only using digital photography and simple illumination screens (Fig. 5F). At first sight, egfp formation in culture was a good proxy for the activity of the cells to detect the presence of metabolizable oil (Fig. 6). For example, the effect of nutrients on oil perception and degradation was very clear, although NSO-1 oil added to seawater alone also produced a very small but significant reporter signal (Fig. 5C). This underscores the importance of balanced nutrition for oildegrading bacteria, what has been concluded extensively before (Kasai et al., 2002; Head et al., 2006). More striking, however, was the strong inductive effect on reporter formation by addition of the oleophilic fertilizer S200, but which did not lead to such extensive alkane degradation as in the case of full nutrient balanced medium (ONR7a). This suggests that whereas such fertilizer had a positive influence on SK-3009 (pAlk8) cells, something in their formulation might actually lead to unproductive induction of the alkB1 pathway or is otherwise inhibiting the cells. In conclusion, we demonstrated that $A$. borkumensis SK-3009 (pAlk8) can be used as a versatile bioreporter in assays to study long-chain alkane bioavailability from a variety of sources and in the presence of treatments that may or may not improve efficacy of oil degradation. Flask-glow assays such as presented in Fig. 5 may prove particularly useful on board of, for example, marine responder vessels.

\section{Experimental procedures}

\section{Chemicals}

Octane (99\% purity) and tetradecane (99\% purity) were purchased from Fluka (Buchs, Switzerland). Eicosane $\left(\mathrm{C}_{20}\right.$, 99\% purity) was purchased from Sigma-Aldrich (Steinheim, Germany). S200 Custom Blend, a commercial oleophilic fertilizer, was purchased from IEP SORBENTS (13250 Daimiel, Ciudad Real, Spain). JBR215 is a commercially produced rhamnolipid solution from Pseudomonas aeruginosa and was obtained from Jeneil Biosurfactant Company (Saukville, USA). Norwegian Geochemical Standard North Sea Oil-1 (NSO-1) was obtained from the Norwegian Petroleum Directorate.

\section{Strains and culture conditions}

Alcanivorax borkumensis strain SK2 was grown on ONR7a (Dyksterhouse et al., 1995) agar plates or liquid medium with 
$10 \mathrm{~g}$ of pyruvate per litre at $30^{\circ} \mathrm{C}$. Escherichia coli strains were routinely grown on Luria-Bertani agar plates or liquid medium at $37^{\circ} \mathrm{C}$ in the presence of appropriate antibiotics (kanamycin, $50 \mathrm{mg} \mathrm{l}^{-1}$; ampicillin, $100 \mathrm{mg} \mathrm{l}^{-1}$; tetracycline, $15 \mathrm{mg} \mathrm{l}^{-1}$ ). Maintenance of pPROBE- and pME6012-based plasmids in $A$. borkumensis was ensured by supplementing spectinomycin (Sp) at $50 \mathrm{mg} \mathrm{l}^{-1}$ and tetracycline at $40 \mathrm{mg} \mathrm{l}^{-1}$ respectively.

\section{Genetic constructions}

A $3.0 \mathrm{~kb}$ fragment containing the complete alk $S_{A b}$ gene, the operator/promoter region of the alkB $B_{1} G H J$ operon and the $5^{\prime}$ extremity of the $a l k B_{1}$ gene (Fig. 1) was amplified by PCR from genomic DNA of strain SK2 using the primers alkS-rev1 (5'-CTCTCGGATCCGCCACTTGCTGCGCACTCGC-3') and alkB1-rev (5'-CTCTCGGTACCGCTCGGTTAAAATGTTCT CTG-3') (introduced restriction sites BamHI and Kpnl are indicated in bold). In addition, a $0.4 \mathrm{~kb}$ fragment containing solely the alkB1p region flanked by the $5^{\prime}$ extremities of alk $S_{A b}$ and $a l k B_{1}$ was amplified by PCR using primers alkS-rev2 (5'-CTCTCGGATCCGATTCGGACTCGGCAGAGGC-3') and alkB1-rev. PCR fragments were cloned into pGEM-T Easy (Promega, Switzerland), subsequently re-isolated by enzymatic restriction using $\mathrm{BamHI}$ and $\mathrm{Kpnl}$, and finally ligated with the vector pPROBE-gfp[tagless] (Miller et al., 2000) cut with the same enzymes. After transformation in $E$. coli this resulted in plasmids pAlk1 and pAlk2 (Fig. 1). A Sp-resistance cassette from pHP $45 \Omega$ (Fellay et al., 1987) was inserted into vectors pAlk1 and pAlk2 at the unique BamHI site to improve plasmid stability in strain SK2. The resulting plasmids were named pAlk3 and pAlk4 respectively (Fig. 1). In these plasmids, the orientation of the Sp-resistance cassette was not defined. To produce a reporter construct with the IUXAB genes plasmid pAlk1 was cut with $\mathrm{EcoRI}$, then treated with the Klenow fragment of DNA polymerase, and finally digested with Sphl. The $3.4 \mathrm{~kb}$ fragment containing the gene alkS $S_{A b}$ and the alkB operator/ promoter region was isolated and purified. The vector pJAMA8 that carried the promoterless luxAB genes (Jaspers et al., 2000) was cut with Xbal, then treated with the Klenow fragment of DNA polymerase and finally digested with Sphl. The alkSAb-alkB, $p$ fragment was ligated with the prepared pJAMA8 vector, which after transformation in $E$. coli resulted in plasmid pAlk5. Finally, because we were not completely satisfied with the stability of plasmids pAlk3 and pAlk4 in strain SK2 we removed the alkS $S_{A b}-a l k B_{1} p$ region fused with egfp from pAlk1 by digestion with BamHI and HindllI, and ligated this to pME6012 (resulting in pAlk8, Fig. 1).

Plasmids were introduced into $A$.borkumensis via triparental mating using E. coli $\mathrm{DH} 5 \alpha$ (pAlk3, pAlk4 or pAlk8) as donors and E. coli HB101 (pRK2013) as helper. Conjugation was allowed to proceed for $16 \mathrm{~h}$ at $30^{\circ} \mathrm{C}$ on the surface of a $0.2 \mu \mathrm{m}$ cellulose acetate filter, after which the mating mixture was resuspended in ONR7a medium and serially diluted. Dilutions were plated and potential transconjugants were selected on ONR7a pyruvate agar plates with $50 \mathrm{mg}$ of Sp per litre (for plasmids pAlk3 or 4) or $40 \mathrm{mg}$ $\mathrm{I}^{-1}$ tetracycline (for pAlk8). We noticed that plasmids pAlk1 and pAlk2 ( $\mathrm{Km}$ resistance) were not stably maintained in SK2. Some E. coli resistance to spectinomycin and tetracy- cline occurred, but these cells only formed tiny colonies that were easily distinguishable from Alcanivorax colonies. Potential SK2 transconjugants were purified multiple times by passage through ONR7a medium and plating, and were differentiated from E. coli by 16S rRNA gene amplification and restriction digestion. The presence and correctness of the conjugated plasmid were verified by PCR and by restriction digestion of isolated plasmid DNA. One such verified strain was maintained as $A$. borkumensis SK-3009 (pAlk8).

\section{Steady-state fluorimetry}

For reporter gene induction in suspended cultures cells were grown until mid-log phase on LB plus $\mathrm{Km}$ or Tc (E. coli strains) or on ONR7a with $10 \mathrm{~g}$ per litre of pyruvate and Tc (SK-3009) or Sp (A. borkumensis pAlk3 or pAlk4). Cells were recovered from their pre-culture by centrifugation at $2500 \mathrm{~g}$ for $10 \mathrm{~min}$, after which the supernatant was removed and the cells were resuspended in MOPS (E. coli) (Tecon et al., 2010) or ONR7a with $10 \mathrm{~g}$ per litre of pyruvate $(A$. borkumensis) to a final culture turbidity at $600 \mathrm{~nm}$ of $\sim 0.4$. Four millilitres of these cell suspensions were distributed in triplicate in $4.5 \mathrm{ml}$ glass HPLC vials with Teflon-lined screw caps (Supelco). Ten microlitres of an alkane stock solution in dimethylsulfoxide (DMSO) was added to each vial in order to obtain final nominal concentrations of between $50 \mathrm{nM}$ and $2 \mu \mathrm{M}$ for octane. Tetradecane and NSO-1 oil were dosed at 5 and $10 \mu \mathrm{l}$ per vial respectively. Two series of triplicate control assays, one with $10 \mu \mathrm{l}$ of DMSO and one without, were carried out simultaneously. Vials were incubated at $20^{\circ} \mathrm{C}$ with orbital shaking at 50 r.p.m. and $0.2 \mathrm{ml}$ of samples were retrieved after $6 \mathrm{~h}$ and $24 \mathrm{~h}$, to measure the intensity of egfp fluorescence (excitation: $480 \mathrm{~nm}$; emission: $520 \mathrm{~nm}$ ) and the culture turbidity (at $600 \mathrm{~nm}$, Fluostar fluorescence microtitre plate reader, BMG Labtechnologies, Germany). eGFP fluorescence intensities were normalized by the culture turbidity.

\section{Bioluminescence assay}

Octane-dependent inducibility of the alk $B_{1}$ promoter in $E$. coli $\mathrm{DH} 5 \alpha$ (pAlk5) and the alkB promoter of $P$. oleovorans in E. coli DH5 $\alpha$ (pGEc74, pJAMA7) (Sticher et al., 1997) was examined using bacterial luciferase (LuXAB) as reporter. Induction assays were prepared with thawed aliquots of reporter cells that had been frozen for storage at $-80^{\circ} \mathrm{C}$ in $15 \%$ glycerol, which were immediately diluted 40 times in MOPS medium. Four millilitres of this reporter cell suspension was added to an $8 \mathrm{ml}$ glass test tube, which was sealed with a borosilicate glass stopper (Verrerie de Carouge, Geneva). The test tubes were previously washed with acetone, rinsed twice with bidistilled water and dried at $80^{\circ} \mathrm{C}$. In the closed test tube, the air/liquid volumetric ratio was approximately $1: 1$. Forty microlitres (1\%) of different octane stock solutions prepared in DMSO, or DMSO alone, were added to each tube in order to obtain the desired nominal concentrations (between 0.1 and $0.8 \mu \mathrm{M}$ ). Five replicate test tubes were used per concentration. The test tubes were incubated at an inclination of $45^{\circ}$, at $30^{\circ} \mathrm{C}$ with shaking (180 
r.p.m.). After $2 \mathrm{~h}$ of incubation, $200 \mu \mathrm{l}$ from each tube was transferred in a white 96-well microtitre plate (Cliniplate, Thermoscientific, Finland). Twenty-five microlitres of an $n$-decanal solution (18 $\mathrm{mM}$ in a water/ethanol solution) was added to each well and mixed by pipetting (final $n$-decanal concentration was $2 \mathrm{mM}$ ). After $3 \mathrm{~min}$ of incubation at room temperature, the bioluminescence was measured using a microtitre plate luminometer (Centro LB 960 luminometer, Berthold AG, Switzerland) with an integration time of $0.1 \mathrm{~s}$.

\section{Agarose gel patch diffusion assays}

Gel diffusion patches were prepared similarly as described earlier (Tecon et al., 2009) but with the following modifications. Alcanivorax borkumensis SK-3009 (pAlk8) was precultured in ONR7a with $10 \mathrm{mM}$ pyruvate and $40 \mathrm{mg} \mathrm{I}^{-1}$ tetracycline. Upon reaching early stationary-phase (16-24 h) cells were centrifuged at $2500 \mathrm{~g}$ for $10 \mathrm{~min}$, prior to be resuspended in ONR7a without pyruvate in order to obtain a culture turbidity of $\sim 0.8$. Five hundred microlitres of this suspension was mixed with a temperated $\left(45^{\circ} \mathrm{C}\right) 0.5 \mathrm{ml}$ molten aliquot of $0.5 \%$ standard agarose (Eurobio, France) in ONR7a plus $1 \mathrm{mM}$ pyruvate. The gel-bacteria suspension was briefly mixed by low-speed vortexing for $30 \mathrm{~s}$ and was pipetted immediately on a round glass coverslip of $25 \mathrm{~mm}$ diameter and $0.17 \mathrm{~mm}$ thickness $(\mathrm{H}$. Saur, Reutlingen, Germany). A $0.5 \mathrm{~mm}$ silicon separator ring and a second similar coverslip were mounted on the gel-bacteria droplet in a POC chamber ( $\mathrm{H}$. Saur, Germany) to form a flat surface. After $45 \mathrm{~min}$ the solidified gel was cut into rectangular strips with approximate dimensions of $0.5 \times 2.0 \mathrm{~cm}$ using a sterile scalpel. Rectangular strips were separated and each individually placed in a new POC chamber on a round coverslip. Agarose strips were then brought into contact with a diffusion source provided via a glass capillary of $0.2 \times 2 \mathrm{~mm}$ (Vitrocom, New Jersey, USA). Glass capillaries were filled at one extremity by capillary force from a $10-12 \mu \mathrm{l}$ source droplet placed hereto in an eppendorf vial. As source we used the following compounds: silicon oil without or with $1 \% \mathrm{v} / \mathrm{v}$ of tetradecane, eicosane without or with $0.1 \%$ or $1 \% \mathrm{v} / \mathrm{v}$ tetradecane, with $1 \%$ or $10 \% \mathrm{v} / \mathrm{v}$ NSO-1. In order to prepare mixtures with eicosane, it was pre-heated to $45^{\circ} \mathrm{C}$ to melt, after which the required volume of tetradecane or NSO-1 was added, the mixture briefly vortexed and taken up in the glass capillary. Two drops of $\sim 10 \mu \mathrm{l}$ of Millipore deionized water were placed on both sides of the gel strip to prevent water evaporation from the patch, after which the POC chamber was closed by placing two Teflon rings of $0.5 \mathrm{~mm}$ thickness and a second coverslip. Finally the system was closed with a metal ring and incubated in a closed box at $28^{\circ} \mathrm{C}$. At 1 -day intervals the egfp fluorescence intensity was measured at positions $0.1 \mathrm{~cm}$ (immediately next to the source), 0.5, 1.0, 1.5 and $2.0 \mathrm{~cm}$ distance from the source, using a Leica DRI4000 fluorescence microscope (Leica Microsystems, Switzerland) at 100× magnification (N PLAN 10×/0.25, Leica). Three images were recorded in the $y$-cross-section at every defined longitudinal distance $(x)$, using a Leica DFC 350FX monochrome camera (Leica Microsystems, Switzerland) with an exposure time of 500 ms using a GFP filter cube (excitation filter: BP 470/40; dichromatic mirror 500; emission filter: BP525/50), and fluorescence intensity (FIM) at 55\%.
Images were exported to METAMORPH (Visitron Systems, Germany) and 12 identical circular regions ( $285 \times 269$ pixels) were distributed over each image area without overlapping. The total grey intensity in each region was measured and averaged per image, and subsequently for each distance. To calculate the total fluorescence intensity increase over time, we first subtracted the background fluorescence signal from every signal-per-distance gradient (as an example, see Fig. 3). The total intensity of the patch at every time moment was then 'integrated' across distance by determining the sum of fluorescence $\times$ distance $(F L D)$ at every position $x_{n}(n=0.1$, $0.5,1.0$ and $1.5 \mathrm{~cm}$ ), as follows:

$$
F L D_{n}=\left(F L x_{n+1}+F L x_{n}\right) / 2 \times\left(D x_{n+1}-D x_{n}\right)
$$

with $F L$ being the average grey intensity at every position and $D$ being the distance in $\mathrm{cm}$ from the source.

\section{Flask reporter assays}

Starting from a single colony, A. borkumensis SK-3009 (pAlk8) was grown in artificial seawater medium (ONR7a) in the presence of $100 \mathrm{mM}$ pyruvate and $40 \mathrm{mg} \mathrm{l}^{-1}$ tetracycline at $30^{\circ} \mathrm{C}$ for $27 \mathrm{~h}$ and with 180 r.p.m. rotation of the culture flask. At a culture turbidity at $600 \mathrm{~nm}$ of $0.5,5 \mathrm{ml}$ of culture was transferred to $95 \mathrm{ml}$ of North Sea seawater (sampled in 2009 , kept at $4^{\circ} \mathrm{C}$ until used) or $95 \mathrm{ml}$ of ONR7a in $250 \mathrm{ml}$ glass Schott flasks for reporter assays. To test response of the $A$. borkumensis SK-3009 (pAlk8) reporter cells, we added $0.5 \mathrm{ml}$ of pure tetradecane or $250 \mu \mathrm{l}$ of NSO-1 crude oil. Moreover, we tested the effect of oleophilic fertilizer (S200) at final concentrations of $0.1 \%(\mathrm{v} / \mathrm{v}), 0.25 \%$ or $1 \%$, and the effect of JBR215 rhamnolipid biosurfactant (at $0.1 \% \mathrm{v} / \mathrm{v}$ ). Triplicate flasks were incubated at room temperature under a chemical hood and with slow shaking (28 r.p.m., Polymax 1040, Heidolph Instruments $\mathrm{GmbH}$, Germany). Flasks were capped but not completely closed so as to allow oxygen penetration. An overview of test set-ups is presented in Table S1. Flasks without $A$. borkumensis SK-3009 (pAlk8) or with $A$. borkumensis SK2 served as controls for autofluorescence of the oils or fertilizer products.

The reporter signal in the assays was measured at regular time intervals by (i) subsampling and fluorimetry (see above), and (ii) direct digital photography of the assay flask. Flasks were hereto illuminated at $470 \mathrm{~nm}$ on a Dark Reader ${ }^{\mathrm{TM}}$ transilluminator (Clare Chemical Research, CO, USA) and photographed at a distance of $50 \mathrm{~cm}$ with a regular digital camera at an exposure time of $1 / 3 \mathrm{~s}$. Images were stored in JPG format and opened in METAMORPH (version 7.03r, Visitron Systems GmbH, Puchheim, Germany). Red and blue colour information was discarded and the intensity of green was measured in six identical circular regions placed without overlapping on the image, and then averaged per image. As a proxy for the amount of $A$. borkumensis biomass we measured absorbance at $600 \mathrm{~nm}$ in a spectrophotometer compared with medium without cells. Fluorescence values were normalized for the culture absorbance.

\section{Extraction procedure for alkane analysis}

To determine the extent of oil degradation in flask assays its content after 7-day incubation time was extracted three times 
with $20 \mathrm{ml}$ of dichloromethane consecutively. Before extraction each sample was spiked with $50 \mu \mathrm{l}$ of a $20 \mathrm{mg} \mathrm{l}^{-1}$ DDTP solution in hexane (DDTP is dodecahydrotriphenylene, quality $99 \%$, Aldrich, Switzerland) per $100 \mathrm{ml}$ total volume. The bidimensional gas chromatography was developed by LECO in Germany. The organic phase from each extraction was recovered and pooled, dried with $\mathrm{Na}_{2} \mathrm{SO}_{4}$ and stored at $-20^{\circ} \mathrm{C}$. Prior to chemical analysis on a comprehensive twodimensional gas chromatograph (GCxGC, Agilent 7890A, LECO, Germany), equipped with FID detector, sample extracts were diluted three times to below $1.11 \mathrm{mg} \mathrm{ml}^{-1}$ final concentration.

\section{Acknowledgements}

We thank Terry McGenity from the University of Essex (UK) for the gift of $A$. borkumensis strain SK2. This work was carried out under the frame of the projects FACEiT and BACSIN, financed by the sixth and seventh framework programmes of the European Community (project $\mathrm{n}^{\circ} 018391$ and KBBE-211684), and further supported by a grant from the Swiss National Science Foundation (LiveSense project). Rekha Kumari acknowledges a BOYSCAST fellowship from the Department of Science and Technology (DST), India.

\section{References}

van Beilen, J.B., Marin, M.M., Smits, T.H., Rothlisberger, M., Franchini, A.G., Witholt, B., and Rojo, F. (2004) Characterization of two alkane hydroxylase genes from the marine hydrocarbonoclastic bacterium Alcanivorax borkumensis. Environ Microbiol 6: 264-273.

Camilli, R., Reddy, C.M., Yoerger, D.R., Van Mooy, B.A., Jakuba, M.V., Kinsey, J.C., et al. (2010) Tracking hydrocarbon plume transport and biodegradation at Deepwater Horizon. Science 330: 201-204.

Denef, V.J., Patrauchan, M.A., Florizone, C., Park, J., Tsoi, T.V., Verstraete, W., et al. (2005) Growth substrate- and phase-specific expression of biphenyl, benzoate, and $\mathrm{C} 1$ metabolic pathways in Burkholderia xenovorans LB400. J Bacteriol 187: 7996-8005.

Dyksterhouse, S., Gray, J., Herwig, R., Lara, J., and Staley, J. (1995) Cycloclasticus pugetii gen. nov., sp. nov., an aromatic hydrocarbon-degrading bacterium from marine sediments. Int J Syst Bacteriol 45: 116-123.

Fellay, R., Frey, J., and Krisch, H. (1987) Interposon mutagenesis of soil and water bacteria: a family of DNA fragments designed for in vitro insertional mutagenesis of Gram-negative bacteria. Gene 52: 147-154.

Gu, M.B., and Chang, S.T. (2001) Soil biosensor for the detection of PAH toxicity using an immobilized recombinant bacterium and a biosurfactant. Biosens Bioelectron 16: 667-674.

Hara, A., and Harayama, S. (2003) Alcanivorax which prevails in oil-contaminated seawater exhibits broad substrate specificity for alkane degradation. Environ Microbiol 5: 746-753.

Hara, A., Baik, S.H., Syutsubo, K., Misawa, N., Smits, T.H., van Beilen, J.B., and Harayama, S. (2004) Cloning and functional analysis of alkB genes in Alcanivorax borkumensis SK2. Environ Microbiol 6: 191-197.
Head, I.M., Jones, D.M., and Roling, W.F.M. (2006) Marine microorganisms make a meal of oil. Nat Rev Microbiol 4: 173-182.

Jaspers, M.C.M., Suske, W.A., Schmid, A., Goslings, D.A.M., Kohler, H.-P.E., and van der Meer, J.R. (2000) HbpR, a new member of the $\mathrm{XyIR/DmpR}$ subclass within the NtrC family of bacterial transcriptional activators, regulates expression of 2-hydroxybiphenyl metabolism in Pseudomonas azelaica HBP1. J Bacteriol 182: 405-417.

Jaspers, M.C.M., Meier, C., Zehnder, A.J.B., Harms, H., and van der Meer, J.R. (2001) Measuring mass transfer processes of octane with the help of an alkS-alkB::gfp-tagged Escherichia coli. Environ Microbiol 3: 512-524.

Jiménez, N., Viñas, M., Sabaté, J., Diez, S., Bayona, J.M., Solanas, A.M., and Albaiges, J. (2006) The Prestige oil spill. II. Enhanced biodegradation of a heavy fuel oil by the use of an oleophilic fertilizer under field conditions. Environ Sci Technol 40: 2578-2585.

Kasai, Y., Shindo, K., Harayama, S., and Misawa, N. (2002) Predominant growth of Alcanivorax strains in oilcontaminated and nutrient-supplemented sea water. Environ Microbiol 4: 141-147.

Leveau, J.H.J., König, F., Füchslin, H.-P., Werlen, C., and van der Meer, J.R. (1999) Dynamics of multigene expression during catabolic adaptation of Ralstonia eutropha JMP134 (pJP4) to the herbicide 2, 4-dichlorophenoxyacetate. Mol Microbiol 33: 396-406.

Liu, C., Wang, W., Wu, Y., Zhou, Z., Lai, Q., and Shao, Z. (2011) Multiple alkane hydroxylase systems in a marine alkane degrader, Alcanivorax dieselolei B5. Environ Microbiol 13: 1168-1178.

Medina-Bellver, J.I., Marin, P., Delgado, A., RodriguezSanchez, A., Reyes, E., Ramos, J.L., and Marqués, S. (2005) Evidence for in situ crude oil biodegradation after the Prestige oil spill. Environ Microbiol 7: 773-779.

van der Meer, J.R., and Belkin, S. (2010) Where microbiology meets microengineering: design and applications of reporter bacteria. Nat Rev Microbiol 8: 511-522.

Miller, W.G., Leveau, J.H.J., and Lindow, S.E. (2000) Improved gfp and inaZ broad-host range promoter-probe vectors. Mol Plant Microbe Interact 13: 1243-1250.

Sabirova, J.S., Ferrer, M., Regenhardt, D., Timmis, K.N., and Golyshin, P.N. (2006) Proteomic insights into metabolic adaptations in Alcanivorax borkumensis induced by alkane utilization. J Bacteriol 188: 3763-3773.

Schneiker, S., Martins dos Santos, V.A., Bartels, D., Bekel, T., Brecht, M., Buhrmester, J., et al. (2006) Genome sequence of the ubiquitous hydrocarbon-degrading marine bacterium Alcanivorax borkumensis. Nat Biotechnol 24: 997-1004.

Sticher, P., Jaspers, M., Harms, H., Zehnder, A.J.B., and van der Meer, J.R. (1997) Development and characterization of a whole cell bioluminescent sensor for bioavailable middlechain alkanes in contaminated groundwater samples. Appl Environ Microbiol 63: 4053-4060.

Sutton, C., and Calder, J.A. (1974) Solubility of higher molecular-weight $n$-paraffins in distilled water and seawater. Environ Sci Technol 8: 654-657.

Tecon, R., and van der Meer, J.R. (2008) Bacterial biosensors for measuring availability of environmental pollutants. Sensors 8: 99-105. 
Tecon, R., Binggeli, O., and van der Meer, J.R. (2009) Double-tagged fluorescent bacterial bioreporter for the study of polycyclic aromatic hydrocarbon diffusion and bioavailability. Environ Microbiol 11: 2271-2283.

Tecon, R., Beggah, S., Czechowska, K., Sentchilo, V., Chronopoulou, P.M., McGenity, T.J., and van der Meer, J.R. (2010) Development of a multistrain bacterial bioreporter platform for the monitoring of hydrocarbon contaminants in marine environments. Environ Sci Technol 144: 10491055.

Yakimov, M., Golyshin, P., Lang, S., Moore, E., Abraham, W., Lunsdorf, H., and Timmis, K. (1998) Alcanivorax borkumensis gen. nov., sp. nov., a new, hydrocarbon-degrading and surfactant-producing marine bacterium. Int J Syst Bacteriol 48: 339-348.

Zhang, D., Fakhrullin, R.F., Ozmen, M., Wang, H., Wang, J.,
Paunov, V.N., et al. (2010) Functionalization of whole-cell bacterial reporters with magnetic nanoparticles. Microb Biotechnol 4: 89-97.

\section{Supporting information}

Additional Supporting Information may be found in the online version of this article:

Table S1. Experimental set-up of $A$. borkumensis SK-3009 (pAlk8) flask reporter assays.

Please note: Wiley-Blackwell are not responsible for the content or functionality of any supporting materials supplied by the authors. Any queries (other than missing material) should be directed to the corresponding author for the article. 